\title{
Spin-Sprayed Ferrite Films Highly Permeable in the GHz Range, with Excellent Heat Resistance
}

\author{
K. Kondo, Y. Numata, T. Chiba, S. Yamada, S. Yoshida, \\ Y. Shimada ${ }^{*}$ N. Matsushita ${ }^{* *}$, and M. Abe ${ }^{* *}$ \\ NEC Tokin Corporation, 6-7-1, Koriyama, Taihaku-ku, Sendai, Miyagi, 982-8510, Japan \\ * Tohoku University, 6-6-05, Aramaki-aza-aoba, Aoba-ku, Sendai, Miyagi, 980-8579, Japan \\ ${ }^{* *}$ Department of Physical Electronics, Tokyo Institute of Technology, 2-12-1 O-okayama, Meguro-ku, Tokyo, 152-8552, Japan
}

Previously we revealed that spin-sprayed ferrite films are usable for GHz-range noise suppressors. For actual use, the films must retain excellent characteristics after the reflow soldering process. In this study, we investigated how changing the compositions of films influences their electric resistivity and the noise suppression effects obtained after annealing at $260^{\circ} \mathrm{C}$. We plated 3- $\mu$ m-thick ferrite films \#1 $\left(\mathrm{Ni}_{0.2} \mathrm{Zn}_{0.1} \mathrm{Fe}_{2.7} \mathrm{O}_{4}\right)$ and \#2 $\left(\mathrm{Ni}_{0.4} \mathrm{Zn}_{0.3} \mathrm{Fe}_{2.3} \mathrm{O}_{4}\right)$ onto polyimide sheets. The resistivity of film \#1 decreased markedly, from $4 \times 10^{2} \Omega \mathrm{cm}$ to $1 \times 10^{0}$ $\Omega \mathrm{cm}$ as a result of the annealing. On the other hand, film \#2 exhibited a smaller decrease, from $6 \times 10^{4} \Omega \mathrm{cm}$ to $2 \mathrm{x}$ $10^{4} \Omega \mathrm{cm}$. The reflection parameter $S_{l l}$ and transmission loss $\Delta P_{\text {loss }}$ measured on a microstrip line for film \#1, especially below $1 \mathrm{GHz}$, were increased by the annealing. This is unfavourable for use of film \#1 in lowpass filters that are required to absorb noises only in the $\mathrm{GHz}$ range. On the other hand, $S_{11}$ and $\Delta P_{\text {loss }}$ for film \#2 were not significantly affected by the annealing. This film exhibited $\Delta P_{\text {loss }}$ of $40 \%$ at $10 \mathrm{GHz}$. Moreover, the value of $S_{11}$ for the film below $10 \mathrm{GHz}$ was sufficiently weak, less than $-12 \mathrm{~dB}$. Thus, we succeeded in fabricating a GHz-range noise suppressor, with excellent heat resistance.

Key words: ferrite plating, Ni-Zn ferrite film, complex permeability, electric resistivity, noise suppressor.

\section{Introduction}

Current advanced downsized electronic equipments, such as Pc's and mobile phones, are currently driven at frequencies higher than several $\mathrm{GHz}$. In such equipments electronic components are densely packed, which tend to cause electromagnetic interferences not only with other equipments but also with other components inside the equipments. Therefore, electromagnetic noise suppressors, which suppress high frequency noise currents generated in semiconductor devices and other components mounted on printed circuit boards, are strongly required at present. We 1) 2) reported that spin-sprayed NiZn ferrite films are usable for the noise suppressors working up to $\mathrm{GHz}$ range, because the films exhibited relatively high complex permeability, $\mu=\mu^{\prime}-j \mu^{\prime \prime}$, even up to $3 \mathrm{GHz}$. The ferrite films had DC resistivity of the order of $10^{4} \Omega \mathrm{cm}$, which is, though, lower than that $\left(10^{6}-10^{7} \Omega \mathrm{cm}\right)$ reported for bulk NiZn ferrites, but yet much higher than that $\left(\sim 10^{-3} \Omega \mathrm{cm}\right)$ reported for metal composite films under development. Moreover, the spin-spaying is a wet process performed at low temperature $\left(\mathrm{T}<90^{\circ} \mathrm{C}\right)$ and enables us to fabricate novel two types of conducted noise suppressors, "direct deposition" type (the ferrite films are directly deposited on noise sources on printed circuit boards) and "sheet type" (the ferrite films are deposited on a flexible polymer sheet, which are cut and placed onto the noise sources). For actual use in noise suppressors, the films must keep the excellent magnetic and electric characteristics unchanged after the reflow soldering process at about $260{ }^{\circ} \mathrm{C}$, especially when the ferrite films are embedded in multilayered printed circuit boards or electronic components. In this study we investigated how changing the compositions of films influence the electric resistivity and the noise suppression effects obtained after annealing at $260^{\circ} \mathrm{C}$.

\section{Experiments}

$\mathrm{Ni}-\mathrm{Zn}$ ferrite films with various compositions were deposited onto polyimide sheets at $90{ }^{\circ} \mathrm{C}$ by spraying a reaction solution and an oxidising solution simultaneously. The films, as deposited and after annealed at $260{ }^{\circ} \mathrm{C}$ for 3 minutes in air, were subjected to the following measurements and analyses. The microstructures and chemical compositions were analysed by scanning electron microscopy (SEM) and inductively coupled plasma spectrometry (ICPS). In-plane DC resistivity was measured using a two-probe surface resistance meter. Complex permeability $(\mu=\mu \prime-j \mu \prime)$ spectra up to $3 \mathrm{GHz}$ were measured using a permeance meter equipped with a shielded loop coil ${ }^{3)}$. To evaluate the noise suppression characteristics the samples were cut into $35 \mathrm{~mm} \times 35 \mathrm{~mm}$ pieces, which were placed onto a $50 \Omega$ microstrip line of $70 \mathrm{~mm}$ length, as described in our previous paper ${ }^{4)}$. Measuring reflection parameter $S_{11}$ and transmission parameter $S_{2 l}$ from $10 \mathrm{MHz}$ to $10 \mathrm{GHz}$ with a network analyzer, we calculated transmission loss $\Delta P_{\text {loss }}$ according to the formulas given in ref. ${ }^{1)}$. For comparison, measurements were also done on a commercialised, composite type noise suppressor ( $25 \mu \mathrm{m}$ thickness) in 
which ferromagnetic metal flakes are embedded in a polymer matrix $^{5)}$

\section{Results and discussion}

The films \#1 and \#2 had compositions $\mathrm{Ni}_{0.2} \mathrm{Zn}_{0.1} \mathrm{Fe}_{2.7} \mathrm{O}_{4}$ and $\mathrm{Ni}_{0.4} \mathrm{Zn}_{0.3} \mathrm{Fe}_{2.3} \mathrm{O}_{4}$, respectively. As shown in Fig.1, the both films had thicknesses of about 3 $\mu \mathrm{m}$. The film \#1 had a relatively thick (ca, several hundred nanometers) columnar structure perpendicular to film plane. On the other hand, the film \#2 had no columnar structure, but was composed of large (reaching several hundred nanometers) grains, having a rough surface. Thus the film \#2 exhibited a weaker adhesive power against substrate than the film \#1.

The resistivity for the film \#1decreased remarkably from $4 \times 10^{2} \Omega \mathrm{cm}$ to $1 \times 10^{0} \Omega \mathrm{cm}$ by the annealing. On the other hand, the film \#2 exhibited a small decrease from $6 \times 10^{4} \Omega \mathrm{cm}$ to $2 \times 10^{4} \Omega \mathrm{cm}$. Electric conduction in ferrite materials is given by transfer of electrons between $\mathrm{Fe}^{2+}$ and $\mathrm{Fe}^{3+}\left(\mathrm{Fe}^{3+}+\mathrm{e}^{-}=\mathrm{Fe}^{2+}\right)$ on the octahedral sites (B-sites) of spinel structure, which is enhanced as concentration of $\mathrm{Fe}^{2+}$ increases. Therefore, we can consider that the film \#1, which was low in $\mathrm{Ni}^{2+}+\mathrm{Zn}^{2+}$ concentration and thus high in $\mathrm{Fe}^{2+}$ concentration (nominal composition: $\mathrm{Ni}^{2+}{ }_{0.2} \mathrm{Zn}^{2+}{ }_{0.1} \mathrm{Fe}^{2+}{ }_{0.7} \mathrm{Fe}^{3+}{ }_{2.0} \mathrm{O}_{4}$ ), exhibited lower resisistivity than the film \#2 which was low in $\mathrm{Fe}^{2+}$ concentration $\left(\mathrm{Ni}^{2+}{ }_{0.4} \mathrm{Zn}^{2+}{ }_{0.3} \mathrm{Fe}^{2+}{ }_{0.3} \mathrm{Fe}^{3+}{ }_{2.0} \mathrm{O}_{4}\right)$.

(a) Film \#1 $\left(\mathrm{Ni}_{0.2} \mathrm{Zn}_{0.1} \mathrm{Fe}_{2.7} \mathrm{O}_{4}\right)$

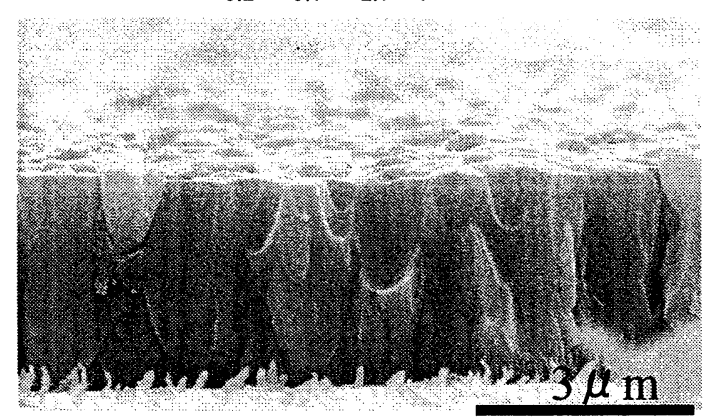

(b) Film \#2 $\left(\mathrm{Ni}_{0.4} \mathrm{Zn}_{0.3} \mathrm{Fe}_{2.3} \mathrm{O}_{4}\right)$

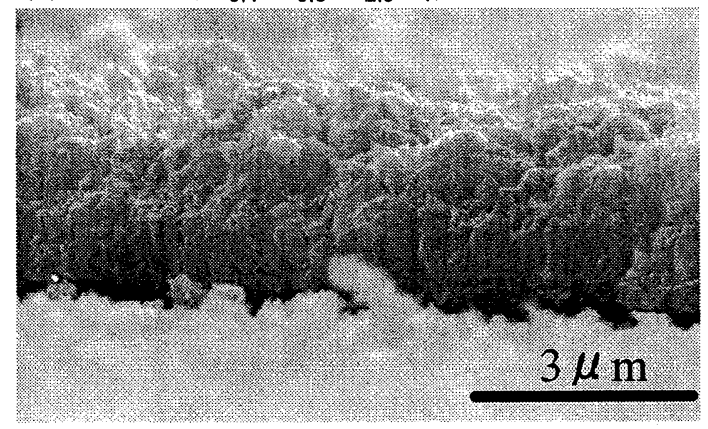

Fig. 1 Cross-sectional SEM images for films \#1 and \#2.

As shown in Fig. 2, $\mu^{\prime}$ in the lower frequency range for both films decreased by the annealing, while the natural resonance frequency $f_{r}$, where $\mu$ " becomes maximum, shifted to the higher frequencies, from 450

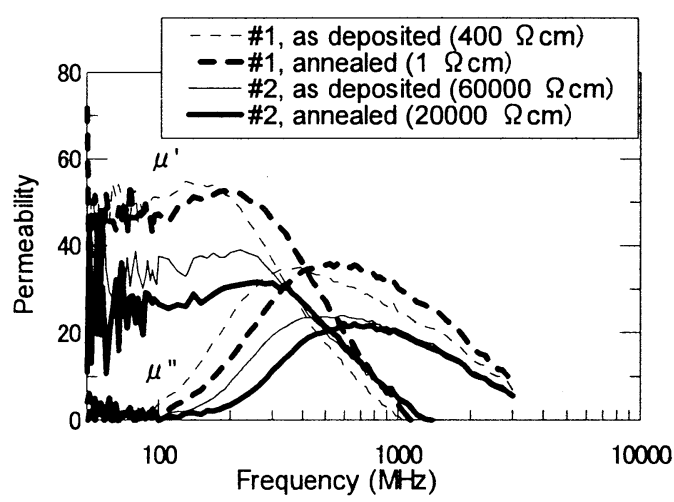

Fig. 2 Permeability spectra for films \#1 and \#2.
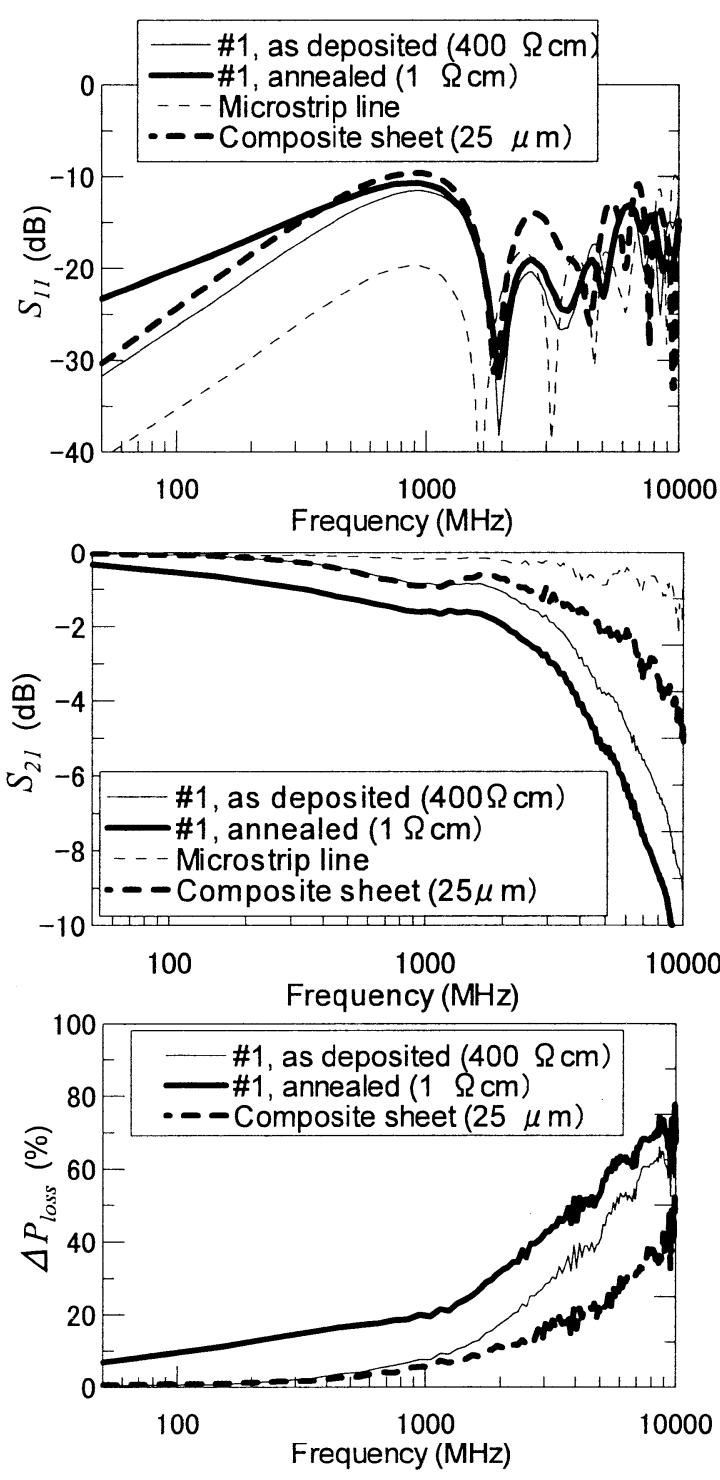

Fig. 3 S-parameters and $\Delta P_{\text {loss }}$ for film \#1 and a composite sheet.

$\mathrm{MHz}$ to $650 \mathrm{MHz}$ for the film \#1 and from $550 \mathrm{MHz}$ to $750 \mathrm{MHz}$ for the film \#2. The change of the permeability spectra by the annealing may be ascribed to the increase in 
uniaxial anisotropy field $H_{k}$, because $\mu^{\prime}$ and $f_{r}$ for the magnetic films (where spins are confined to film plane) are expressed by the following equations based on two dimensional spin dynamics ${ }^{6}$.

$$
\begin{gathered}
\mu^{\prime}=\frac{4 \pi M_{s}}{H_{k}} \\
f_{r}=\frac{\gamma}{2 \pi} \sqrt{H_{k} \cdot 4 \pi M_{s}}
\end{gathered}
$$

Here $M_{s}$, and $\gamma$ represent saturation magnetization and gyromagnetic ratio. Since we observed no remarkable change in microstructure of both films by the annealing, we guess that the increase of $H_{k}$ as well as the decrease of resistivity by the annealing are caused by the change in valence or distribution of cations. We also guess that the lower permeability of the film \#2 is ascribed to the lower $M_{s}$ of $470 \mathrm{emu} / \mathrm{cc}$ than that of the film \#1 of $220 \mathrm{emu} / \mathrm{cc}$, mainly due to the deterioration of microstructure shown in
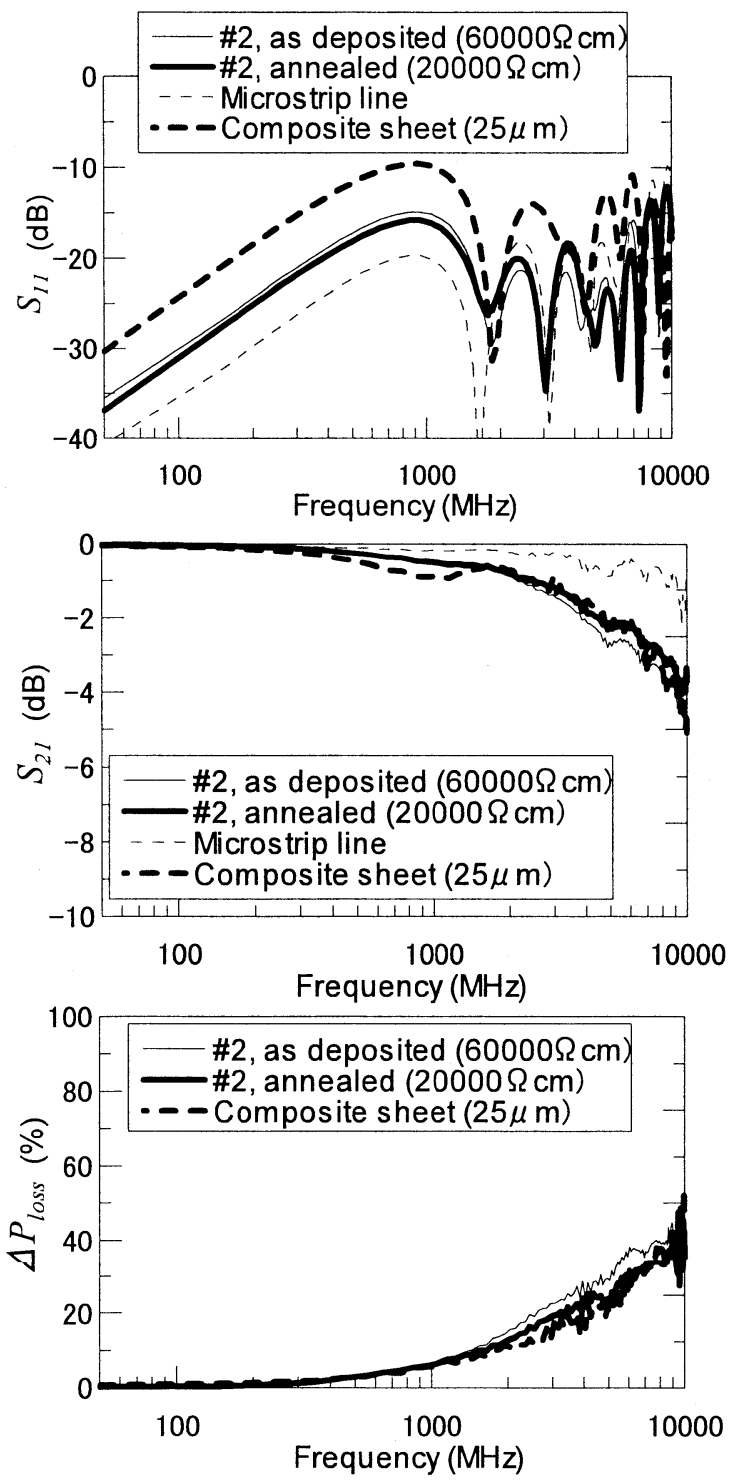

Fig. 4 S-parameters and $\Delta P_{\text {loss }}$ for film $\# 2$ and a composite sheet.
Fig.1. In order to improve the permeability as well as the adhesive power against substrate, modifying the morphology of grains, by changing the plating conditions, will be necessary.

As shown in Fig.3, $S_{11}$ for the film \#1, especially at below $1 \mathrm{GHz}$, increased by the annealing, while $S_{21}$ decreased. $\Delta P_{\text {loss }}$ for the film \#1 increased by the annealing throughout the measurement frequency range, which is reflecting the changes occurred in $S_{I I}$ and $S_{2 I} . \Delta P_{\text {loss }}$ for the film \#1 after the annealing was much stronger than that for the composite sheet of $25 \mu \mathrm{m}$ thickness. However, $S_{I I}$ for the film \#1 after the annealing was higher than that for the composite sheet below $300 \mathrm{MHz}$, and moreover, $\Delta P_{\text {loss }}$ was relatively high even at below $1 \mathrm{GHz}$. This is unfavourable for the use as lowpass filters that are required to absorb noises only in the $\mathrm{GHz}$ range. As shown in Fig. 4, on the other hand, $S_{l l}$ and $\Delta P_{\text {loss }}$ for the film \#2 did not change much by the annealing, though $\Delta P_{\text {loss }}$ was lower than that for the film \#1 due to the lower $\mu$ ". The reflection parameter $S_{11}$ for the film \#2 was less than -12 $\mathrm{dB}$ below $10 \mathrm{GHz}$, being much lower than that reported for the composite sheet. Moreover, $\Delta P_{\text {loss }}$ for the film \#2 at $10 \mathrm{GHz}$ was $40 \%$, which is as strong as that reported for the composite sheet. This means that the film \#2 of $3 \mu \mathrm{m}$ thickness exhibits not only excellent heat resistance but also strong noise suppression. Since the film \#1 is eight times thinner than the composite sheet, our film exhibits noise suppression eight times stronger than the composite sheet.
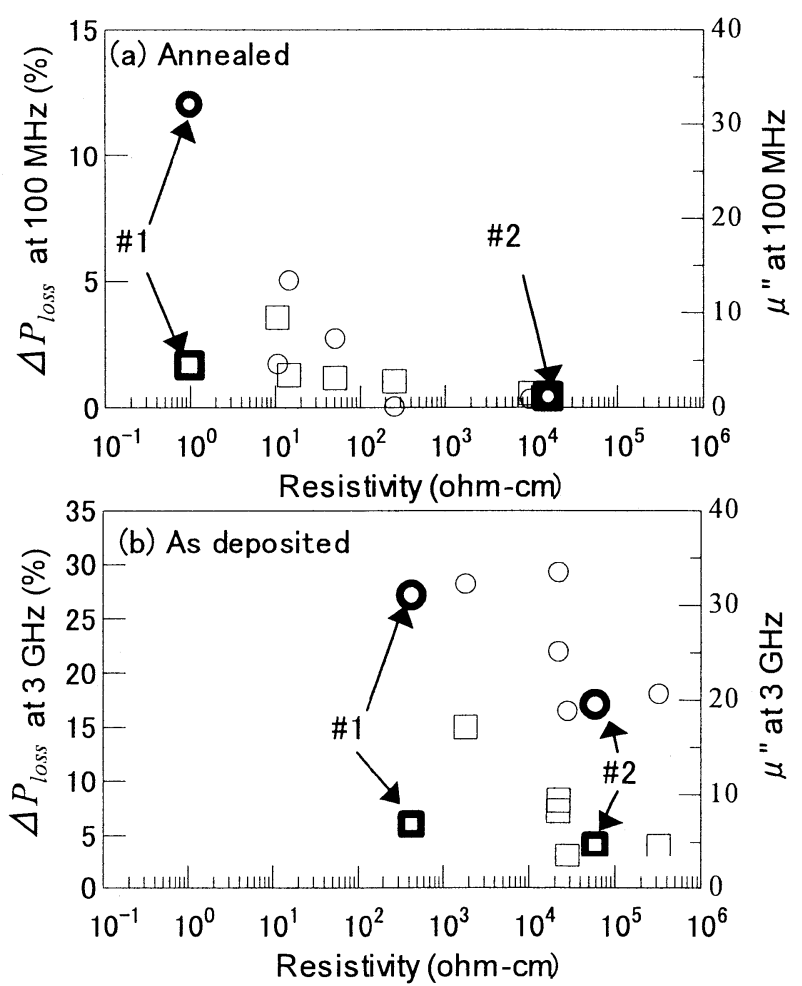

Fig. 5 Resistivity dependence of $\Delta P_{\text {loss }}$ (shown by circles) and $\mu$ " (shown by squares) at (a) $100 \mathrm{MHz}$ and (b) $3 \mathrm{GHz}$, obtained for various annealed and as-deposited films, including \#1 and \#2. 
We can consider that the increase of $\Delta P_{\text {loss }}$ by the annealing for the film \#1 is ascribed to the remarkable decrease of resistivity, because, as shown in Fig.5(a), $\Delta P_{\text {loss }}$ for various annealed films (prepared in addition to $\# 1$ and \#2) decreased with increasing resistivity at 100 $\mathrm{MHz}$ where $\mu$ " was negligibly small. One possible origin of the resistivity-related power loss described above is in-plane eddy current loss caused by the incident magnetic flux perpendicular to the film plane. We can also consider that $\Delta P_{\text {loss }}$ in $\mathrm{GHz}$ range for the as-deposited films (with resistivity higher the $10^{2} \Omega \mathrm{cm}$ ) is mainly ascribed to $\mu$ ", because, as shown in Fig.5(b), the sample having higher $\mu$ " tends to exhibit stronger $\Delta P_{\text {loss }}$ at $3 \mathrm{GHz}$ (the upper frequency limit of our permeability measurements).

\section{Conclusions}

We successfully fabricated thin film $\mathrm{GHz}$ noise suppressor of $3 \mu \mathrm{m}$ thickness from aqueous solution, having an excellent heat resistance. The films will keep the excellent magnetic and electric characteristics unchanged even after reflow soldering process at about $260{ }^{\circ} \mathrm{C}$, which enable us to realize electromagnetic noise suppressors which are embedded in printed circuit boards and electronic parts. Modifying the morphology of grains, by changing the plating conditions, is the issue to be addressed, which may enhance the noise suppression performance further and improve the adhesion power against substrates.
Acknowledgements This work was supported in part by a Support Program for Technology Development on the Basis of Academic Findings, from New Energy and Industrial Technology Development Organization (NEDO), Japan.

We would also like to express our cordial thanks to Professor Masahiro Yamaguchi, Graduate School of Engineering, Tohoku University, and Doctor Masaru Tada, Tokyo Institute of technology, for very fruitful discussions.

\section{References}

1) K. Kondo, T. Chiba, H. Ono, S. Yoshida, Y. Shimada, N. Matsushita, and M. Abe: J. Appl. Phys., 93, 7130 (2003).

2) N. Matsushita, K. Kondo, H. Ono, S. Yoshida, and M. Abe: Trans. Magn. Soc. Japan, 3,129 (2003).

3) M. Yamaguchi, S. Yabukami, and K. I. Arai: IEEE Trans. Magn., 32, 4941 (1996).

4) K. Kondo, T. Chiba, H. Ono, S. Yoshida, Y. Shimada, N. Matsushita, and M. Abe: Proc. ICF-9, 659 (2004).

5) S. Yoshida, M. Sato, E. Sugawara, and Y. Shimada: $J$. Appl. Phys., 85, 4636 (1999).

6) R. M. Walser, W. Win and P. M. Vlanju, IEEE Trans. Magn., 34, 1390 (1998).

Received May. 25, 2005; Accepted Jul. 15, 2005. 